\title{
Advancing the Health and Quality of Life of Girls and Women after Traumatic Brain Injury: Workshop Summary and Recommendations
}

Harris JE, Colantonio A, Bushnik T, Constantinidou F, Dawson D, Goldin-Lauretta Y, Swaine B, Warren J, and the Women and Girls' Traumatic Brain Injury Task Force.

\begin{abstract}
Purpose: To disseminate findings from an international workshop regarding priority issues for girls' and women's health and quality of life after sustaining a traumatic brain injury (TBI).

Methods: A workshop was held prior to the American Congress of Rehabilitation Medicine Conference 2010. The purpose of the workshop was to highlight the unique health issues experienced by women after a TBI, to identify research, education, and policy gaps and to develop strategies to promote women's health. Presentations by researchers and consumers as well as large group discussions formed the basis of the recommendations.

Results: Twenty researchers, clinicians, consumers, and community agency personnel attended from five countries. Significant gaps in service provision in the community were identified as were unique issues for the short- and long-term effects on maturation and aging, reproductive and sexual health, mental health, and life satisfaction. The workshop led to the development of an international task force and recommendations for future directions.
\end{abstract}

Conclusion: Women and girls experience unique outcomes after a TBI. The workshop identified research, policy, education, and service priorities for the promotion of health and quality of life within this population.

\section{Word count: 186}




\section{Introduction}

Traumatic brain injury (TBI) is a leading cause of death and disability globally with nearly 2 million individuals in North America sustaining an injury each year [1]. Studies estimate that approximately $30 \%$ of injuries are sustained by women [2, 3]. Additionally, research has found gender differences in physiological $[4,5]$, cognitive [6], psychological [7, 8], and community living outcomes [9]. Surprisingly, despite indication of gender differences, there is a lack of systematic research in investigating the specific outcomes of TBI in women survivors. Gender differences in relation to TBI are applicable across the lifespan.

Few pediatric studies examine outcomes based on sex; although, some studies have found important differences in incidence $[10,11]$, post concussive symptoms $[12,13]$, and functional outcomes [14]. Within the pediatric population, sustaining a TBI during childhood could lead to deficits that impede physical, cognitive, and psycho-social development $[15,16,17]$. In turn, these deficits can cause long term neuro-endocrine cascades affecting hormonal development (and puberty) [18], and hamper the effectiveness of transitional stages (e.g. from school to work) [19]. Girls who survive a TBI grow up to become women with chronic disabilities. Various studies have demonstrated that females with disability are at greater risk for inadequate medical care [20], abuse, and violence [21, 22]. Despite these differences little research or formulation of clinical guidelines has been advanced specific to women's health after TBI.

The results of the aforementioned studies represent a starting point to investigate the impact of TBI on women in all areas of health and quality of life across the lifespan. Clinician guidelines, community agency mandates, and health services policy need to address the medical, psychological, and social needs that frequently affect female survivors of TBI from initial injury 
into the chronic stages. Further, there is a role for healthcare providers as advocates for the development of greater supports specific to women survivors of TBI.

As a method to promote better health, quality of life and health service delivery for women with TBI, a team planning and knowledge mobilization grant was obtained from the Canadian Institutes of Health Research for a one day workshop. The main purpose of the workshop was to develop national and international partnerships among clinicians, researchers, agencies, and consumers and their advocates for the advancement of women's health after TBI. The workshop aimed to focus on three areas of women's health acknowledging the possible changing needs according to life stage: biological (e.g. reproductive health, menopause, and physical and cognitive disability), psychological (e.g. depression/anxiety and coping abilities), and social (e.g. isolation, family, role resumption). The following specific objectives guided the workshop:

1. Disseminate existing knowledge of women's health post TBI from research, clinician expertise, and consumer experience,

2. Identify and reach consensus on strategies to address research, education, policy, and advocacy gaps,

3. Develop strategies on dissemination of workshop findings,

4. Develop a network of researchers, clinicians, agencies, and consumer groups to build research capacity in order to implement strategies and address research priorities.

The workshop was held as part of the pre-conference agenda during the 2010 American Congress of Rehabilitation Medicine in Montreal, Canada. An international group of twenty researchers, clinicians, community agencies, and consumers were brought together. The 
activities included a keynote address by Alana Officer, Director of Disability and Rehabilitation at the World Health Organization (WHO), who presented global activities relevant to TBI and women. The agenda featured knowledge exchange among consumers, clinicians, consumers and their advocates relevant to improving the current state of health and community services, the need for clinician education, and consumer advocacy. During the workshop, a member of the grant team recorded the discussion in written and audio formats. This information was then collated to describe the results of the workshop. The results will be described in the following sections, according to the original objectives.

\section{Objective 1: Disseminate existing knowledge of women's health post TBI from research, clinician expertise, and consumer experience.}

The workshop opened with a presentation on the WHO's global perspective on women and TBI. The WHO has developed a core data set for TBI based on the International Classification of Function and Disability [27]. The presenter also discussed the WHO's initiative on girls/women and poverty, and its relationship with disability [28]. Six research presentations were then given covering the areas of neuroendocrine disorders [23], reproductive health [4], parenting [24], and community integration [25, 26]. The focus of the presentations was on post injury sequelae and secondary injury prevention; the findings from these presentations support and add vital information about the unique issues experienced by females after brain injury. Additionally, the findings helped formulate further research, education, and policy recommendations. A core element of the workshop consisted of presentations by female survivors of brain injury who reported their experience with health services, community integration, and adaptation to life after brain injury. The following is a summary of the key points they emphasized. 
- Limited provision of comprehensive community based services.

- Fatigue and its effect on all aspects of life e.g. not able to work full days. One woman commented, 'just trying to walk from one end of the room to the other is exhausting.'

- Medical approach was negative, left feeling hopeless about recovery. Clinicians promote a generalist approach which did not allow for individuality or goals common among women. For example female patients expressed their desire to dress feminine (e.g. wear high-heel shoes, make-up). These needs were discounted because of balance or safety concerns and ease of dressing. Personal goals related to these issues were reported to be trivialized or dismissed as frivolous even though physical appearance plays an important role in expressing one's identity as female and as a sexual being.

- Negative interactions with the medical/rehabilitation community reported, e.g. treated like they did not understand or need to know the treatment being prescribed, treated like a child, dignity 'trampled'. Could not emphasize enough the feeling of being stigmatized by the medical and public community.

- Some clinicians did not acknowledge or understand the need to grieve the loss of personal identity and to incorporate the 'old self' with the 'new self'; clinicians do not recognize how disability can affect self concept, sexual and/or gender identity.

- Concerns regarding the effects of prolonged amenorrhea which is typical among women after TBI, with possible side effects such as hirsutism and osteoporosis.

- Pervasive attitudinal assumptions by the general community were described, e.g. our panel of survivors encountered prejudice and assumptions that women with TBI are disinhibited and promiscuous. 
The workshop included a broad range of health professionals who also reported specific challenges with respect to caring for women with TBI. These issues arose during an open forum after the presentations from guest speakers and the women survivors. Key concerns are listed below.

\section{Clinician Concerns}

- Challenges regarding counseling women with brain injuries who wish to have children with abusive partners, or who potentially are not able to carry babies to term.

- Possibility of missing abuse among girls/women with TBI because the symptoms can be similar to TBI sequelae e.g. depression, lack of motivation, poor concentration.

- Difficulty carrying out appropriate treatment plans, including personal goals, because of systemic constraints e.g. standard length of stay can be too short, high case load especially in the community, and lack of community resources is prohibitive.

Based on presentations and open discussion of all participants, the following key areas for research and knowledge transfer were determined.

\section{Research}

- To examine the short and long term physiological, cognitive, psychological, sociological, vocational, and economic (public and personal) effects of sustaining a TBI across the life span.

- To determine access to and delivery of appropriate services from the emergency room to the community. 
- To determine the impact of geographic and economical circumstances on access and delivery of services.

- To determine the impact on care-givers and family relationships.

- To examine intentional (via abuse/violence) TBI among girls and women.

- To examine the consequences on the maturation and aging processes.

Research needs to start with survivors in order to understand and prioritize issues. It was recommended that qualitative methods of research such as focus groups begin this process.

\section{Training and Knowledge Transfer}

- Lack of clinician knowledge, expertise, and sensitivity regarding:

1. Female gender-specific short and long term consequences of TBI, including the need for on-going support for mental health, parenting, return to work, and managing day to day activities were identified as key areas.

2. Counseling girls and women about sexuality, sexual behavior, and relationships.

3. Maturation process, arrested or delayed development, aging.

4. Family based intervention.

- Lack of knowledge in the legal and insurance community as well as the general public Group consensus was found for knowledge exchange using conferences, teaching and training opportunities, as well as hosting events with the legal community.

Representatives from community and advocacy groups identified the need to involve government agencies at all levels in order to actively advance the agenda outlined at this workshop. The following key areas were identified. 


\section{Policy}

- Involvement of government agencies to develop a national brain injury strategy and guidelines of care that include unique issues of women and girls.

- Ascertain the allocation of money to acute, rehabilitation, and community services and address insufficiencies when necessary.

\section{Objective 2: Identify and reach consensus on strategies to address these gaps.}

A Task Force on Girls' and Women's Health after TBI was proposed as part of the Brain Injury Special Interest group (BI-ISIG) of the American Congress of Rehabilitation Medicine to move the research agenda forward. The importance of including a pediatric population in our agenda was highlighted. This task force would include survivors, clinicians, community agencies and advocacy groups, and researchers. Sub-groups to address specific areas of concern have been created, although it is understood that they are not mutually exclusive and can span life stages:

1. Violence and Abuse

2. Aging

3. Psychological and Emotional Health

4. Girls and Adolescence

5. Community Integration

6. Reproductive and Sexual Health

- Develop strong collaborative partnerships with community and consumer advocacy groups. This has begun with the Brain Injury Associations of America and Canada, and the Disabled Women's Network (DAWN) of Canada. 
- Develop strong collaborative partnerships with government personnel at all levels.

- Teleconference meetings with the main task force and each sub-group will occur on a monthly basis or as necessary.

\section{Objective 3: Develop strategies on dissemination of workshop findings.}

In order to meet this objective, a web log (blog) (http://yojahealth.blogspot.com/) has been developed to facilitate communication between workshop attendees; plans to expand the blog to the public domain are in progress. Our goal is to post findings on websites that reaches consumer, research, agency, and clinical audiences (e.g. American Congress of Rehabilitation Medicine, University of Washington Knowledge Translation Program, Toronto Rehabilitation Institute, Brain Injury Associations of America and Canada, the European Brain Injury Society, and International Brain Injury Association, Braininjury.com). In addition, it was proposed that we translate findings from this workshop into different languages and post on the Brain Injury Association of Canada, health professional organizations in Quebec and France (French), health professional organizations in Spain. Publishing the findings of the workshop in a scientific journal was a goal to disseminate the information.

\section{Objective 4: Develop a network of researchers, clinicians, agencies, and consumer groups} to build research capacity in order to implement strategies and address research priorities.

The International Task Force on Girls' and Women's Health after Traumatic Brain was formed as means to address this objective.

\section{Conclusions}


Research and consumer reports have identified unique consequences of TBI for girls and women. Yet, there is scant information regarding girls' and women's health after TBI. The workshop attendees identified research, education, policy and advocacy priorities. At present it is unclear what the long term health and quality of life outcomes are for females with TBI, particularly with regard to maturational and aging issues. There is a strong recommendation for participatory research. The intention of the task force resulting from this workshop is to highlight women and brain injury in order to 1) optimize screening, assessment and treatment, 2) influence future research and clinical guidelines, 3) support the education of clinicians and the public and 4) develop and support advocacy initiatives. 


\section{Acknowledgements}

Funding for this study for AC, JEH, BRW, DD, DV, HL, KKY, PK was obtained from a Canadian Institutes for Health Research Meetings, Planning and Dissemination Grant: Gender, Sex and Health (201006MHG). Funding for JEH was obtained by a CIHR Fellowship Award and a Strategic Training Fellowship in Health Care, Technology and Place (FRN: STP 53911). Additional funding for AC was obtained from the Canadian Institutes for Health Research (200603MOP). We recognize a grant from the Ontario Ministry of Health and Long Term Care to the Toronto Rehabilitation Institute and the support of the Toronto Rehabilitation Institute Foundation. We also acknowledge the support of the American Congress of Rehabilitation Medicine.

\section{Declaration of Interest}

There is no conflict of interest from any author. 
Pre-Print version

\section{References}

[1] Corrigan JD, Selassie AW, Orman JA. The epidemiology of traumatic brain injury. Journal of Head Trauma and Rehabilitation 2010;25:72-80.

[2] Colantonio A, Saverino C, Zagorski B, Swaine B, Lewko J, Jaglal S, Vernick L. Hospitalizations and emergency department visits for TBI in Ontario. Canadian Journal of Neurological Sciences 2010;37:783-790.

[3] Tagliaferri F, Compagnone C, Korsie M, Servadei F, Kraus J. A systematic review of brain injury epidemiology in Europe. Acta Neurochirurgica 2006;148:255-268.

[4] Colantonio A, Mar W, Yoshida K, Escobar M, Velikonja D, Rizoli S, Cusimano M, Cullen N. Women's health outcomes after traumatic brain injury. Journal of Women's Health 2010;19:1-8.

[5] Ripley DL, Harrison-Felix C, Sendroy-Terrill M, Cusick CP, Dannels-McClure A, Morey C. The impact of female reproductive function on outcomes after traumatic brain injury. Archives of Physical Medicine and Rehabilitation 2008;89:1090-1096.

[6] Niemeier JP, Marwitz JH, Lesher K, Walker WC, Bushnik T. Gender differences in executive functions following traumatic brain injury. Neuropsychological Rehabilitation 2007;17:293-313.

[7] Schopp L, Shigaki C, Johnstone B, Kirlpatrick H. Gender differences in cognitive and emotional adjustment to traumatic brain injury. Journal of Clinical Psychology in Medical Settings 2001;8:181.

[8] Bay E, Sikorskii A, Saint-Arnault D. Sex differences in depressive symptoms and their correlates after mild-to-moderate traumatic brain injury. Journal of Neuroscience Nursing 2009;41:298-311. 
[9] Slewa-Younan S, van den Berg S, Baguley IJ, Nott M, Cameron ID. Towards an understanding of sex differences in functional outcome following moderate to severe traumatic brain injury: a systematic review. Journal of Neurology, Neurosurgery, and Psychiatry 2008;79:1197-1201.

[10] Adamo MA, Drazin D, Smith C, Waldman JB. Comparison of accidental and nonaccidental traumatic brain injuries in infants and toddlers: demographics, neurosurgical interventions and outcomes. Journal of Neurosurgery Pediatrics 2009;4:414-419.

[11] Bowman SM, Bird TM, Aitken ME, Tilford JM. Trends in hospitalizations associated with pediatric traumatic brain injuries. Pediatrics 2008;122;988-993.

[12] Blinman TA, Houseknecht E, Snyder C, Wiebeb DJ, Nance ML. Postconcussive symptoms in hospitalized pediatric patients after mild traumatic brain injury. Journal of Pediatric Surgery 2009;44:1223-1228.

[13] Gessel LM, Fields SK, Collins CL, Dick RW, Comstock RD. Concussions among United States high School and collegiate athletes. Journal of Athletic Training 2007;42:495-503.

[14] Morrison WE, Arbelaez JJ, Fackler JC, De Maio A, Paidas CN. Gender and age effects on outcome after pediatric traumatic brain injury. Pediatric Critical Care Medicine 2004;5:145-151.

[15] Max JE, Koele SL, Castillo CC, Lingren SD, Arndt S, Bokura H, Robin DA, Smith WL, Sato Y. Personality change disorder in children and adolescents following traumatic brain injury. Journal of the International Neuropsychological Society 2000;6:279-289.

[16] Babikian T, Asarnow R. Neurocognitive outcomes and recovery after pediatric TBI: metaanalytic review of the literature. Neuropsychology 2009;23:283-296.

[17] Noggle CA, Pierson EE. Psychosocial and behavioral functioning following pediatric TBI: 
Pre-Print version

presentation, assessment, and intervention. Applied Neuropsychology 2010;17:110-115.

[18] Niederland T, Makovih H, Gal V, Andreka B, Abraham CS, Kovacs J. Abnormalities of pituitary function after traumatic brain injury in children. Journal of Neurotrauma 2007; 24:119-127.

[19] Semrud-Clikeman M. Pediatric Traumatic Brain Injury: Rehabilitation and transition to home and school. Applied Neuropsychology 2010;17:116-122.

[20] Tate DG, Roller S, Riley B. Quality of life for women with physical disabilities. Physical Medicine and Rehabilitation Clinics of North America 2001;12:23-37.

[21] Rosen DB. Violence and exploitation against women and girls with disability. Annals of the New York Academy of Sciences 2006;1087:170-177.

[22] Casteel C, Martin SL, Smith JB, Gurka KK, Kupper LL. National study of physical and sexual assault among women with disabilities. Injury Prevention: Journal of the International Society for Child and Adolescent Injury Prevention 2008;14:87-90.

[23] Srinivasan L, Roberts B, Bushnik T, Englander J, Spain DA, Steinberg GK, Ren L, Sandel ME, Al-Lawati Z, Teraoka J, et al. The impact of hypopituitarism on function and performance in subjects with recent history of traumatic brain injury and aneurysmal subarachnoid haemorrhage. Brain Injury 2009;23:639-48.

[24] Goldin-Lauretta Y, Spielman L, Tsaousides T, Gordon W, Cantor, J. Biological parenthood following traumatic brain injury: examination of rates and factors related to having children after TBI. Annual Conference of the American Congress of Rehabilitation Medicine; 2010 Oct 20-23; Montreal, Canada.

[25] Bushnik T. Traumatic brain injury model systems of care 2002-2007. Archives of Physical Medicine and Rehabilitation 2008;89:894-5. 
Pre-Print version

[26] Colantonio A, Harris JE, Ratcliff G, Chase S, Ellis K. Gender differences in self reported long term outcomes following moderate to severe traumatic brain injury. BMC Neurology 2010;10:102.

[27] Bernabeu M, Laxe S, Lopez R, Stucki G, Ward A, Barnes M, Kostanjsek N, Reed G, Tate $\mathrm{R}$, Whyte J, et al. Developing core sets for persons with traumatic brain injury based on the international classification of functioning, disability, and health. neurorehabilitation and neural Repair 2009;23:464-467.

[28] World Health Organization [Internet]. 2010 - [cited 2010 Jan 5]; Available from: http://www.who.int/gender/en/ 